\title{
A Simulation Model for a Hybrid-Electric Craft in Restricted Waters
}

\author{
Francesco Mauro, Ubaldo la Monaca, Alberto Marinò, and Vittorio Bucci \\ Department of Engineering and Architecture, University of Trieste, Via Valerio 10, Trieste 34127, Italy \\ Correspondence should be addressed to Vittorio Bucci; vbucci@units.it
}

Received 18 July 2019; Revised 18 March 2020; Accepted 18 June 2020; Published 14 July 2020

Academic Editor: Maria C. Falvo

Copyright (C) 2020 Francesco Mauro et al. This is an open access article distributed under the Creative Commons Attribution License, which permits unrestricted use, distribution, and reproduction in any medium, provided the original work is properly cited.

\begin{abstract}
Sustainable mobility is one of the most challenging issues for passenger transport inside environmental protected areas and ecologically fragile environments. To reduce the pollutant emissions, the adoption of electric or hybrid-electric solutions for crafts propulsion is a suitable option for green navigation. However, the operation in restricted basin leads also to specific critical issues for the vessel sailing, as dealing with shallow or restricted waters and transit under low air-gap bridges. The combination of these constraints with the adoption of a hybrid-electric propulsion system increases the design difficulties also for a small craft, requiring the use of advanced simulation models to assess the vessel performances. This work presents a simulation model for a small passenger craft that will operate in the Grado Lagoon. The model combines the hydrodynamic issues of manoeuvring and propulsion in restricted water with the simulation of the electric loads and capacity of the energy storage system installed onboard. The simulations performed with the developed simulation system are in accordance with data measured during trials on a prototype of the vessel. The developed model is a powerful tool for designers in order to rapidly assess the green capabilities of new projects since the early design stages.
\end{abstract}

\section{Introduction}

With the increase in public awareness on environmental preservation, air pollutants from ship exhaust emissions are addressed with more and more attention [1,2]. Many studies presented that nitrogen oxides $\left(\mathrm{NO}_{\mathrm{x}}\right)$, sulfur oxides $\left(\mathrm{SO}_{\mathrm{x}}\right)$, and particulate matter (PM) emitted from international shipping account for 13\%, 12\% [3], and 1\% [4] of total global $\mathrm{NO}_{\mathrm{x}}, \mathrm{SO}_{\mathrm{x}}$, and $\mathrm{PM}$ emissions, respectively. Moreover, ship emissions in ports may have a significant impact on local air quality, population exposure, and, therefore, human health in harbour cities. Furthermore, it should not be forgotten that in many areas of the planet, ship traffic does not only involve sea routes but also inland waterways and, for tourism purposes, particularly sensitive natural areas such as rivers and lagoons. Besides, the majority of scientific studies report ground-based measurements collected at remote inland observation spots. The main consequence of public opinion is that ships can be considered among the largest source of air pollution. In particular, air pollutants emitted from ships in river ports, inland waterways, and restricted basins have a direct impact on local air quality and pose a threat to the health of residents, tourists, and animal species [5].

As a result of the importance of the climate change challenge, the International Maritime Organization (IMO) has strongly developed and implemented new measures to address pollutant emissions from ships. However, since these regulations [6] are de facto compulsory only for ships that are used for international travel, further standards have been issued by international, national, and local bodies [7].

The introduction of this new regulation framework addressed current research on new design and management approaches for more efficient and greener propulsion systems. The recent literature reports many technological options, mainly based on the adoption of hybrid-electric systems with onboard energy storage systems. For small passenger crafts, the situation is even more critical once it is requested to operate close to urban areas or in natural 
reserves. The adoption of hybrid-electric propulsion is particularly suitable in such cases $[8,9]$, where no high power demand is necessary due to speed limits in restricted areas, making the so-called Zero-Emission Mode (ZEM) possible $[10,11]$.

The typical system architecture considers that the onboard generation system has to satisfy the propulsion and electrical loads; it consists of thermomechanical and electrical sections. The thermomechanical section is typically made by thermal prime movers, such as Diesel engines, while the electrical section typically consists of synchronous machines, supplying AC and/or DC distribution systems [12]; generally, the whole is accompanied by energy storage systems, typically batteries. In particular, the presence of energy storage in the onboard power system can increase the efficiency of prime movers in order to reduce fuel consumption and pollutant emissions.

This kind of improvement led to the construction of passenger crafts for sustainable navigation in protected and urban areas. However, in order to enable the ZEM navigation, it is necessary to predict the power demand for a selected route, considering the speed limitations and the specific environment the vessel has to face. The navigation in inland waterways, coastal areas, or in lagoons implies the operation in restricted waters [13]. Here, the determination of the propulsive loads is not an easy task. Shallow water has an impact on both resistance/propulsion and manoeuvring of the vessel, making a dedicated simulation of the real working environment necessary for design issues [14]. The determination of the propulsive loads has an impact on the selection of the energy storage system to be installed onboard for performing ZEM navigation on a specific route. Through this paper, from a campaign of surveys performed during the trials of a real inland water passenger craft prototype, a route simulation model for inland and coastal navigation [15] has been enhanced to include the possibility to evaluate the state of charge of the battery packs installed onboard, considering the real power demand during a route. The main service routes of the passenger craft have been simulated to ensure the compliance of the battery packs capacity with the operative profile of the unit, taking into account the need to have sufficient energy capacity to fully perform the service in ZEM profile.

Thanks to the validation with trials measurements, the developed simulation model can be considered a reliable tool for green craft designers to be used in the early design stages of new projects in order to assess the ZEM performances of the vessel.

\section{Working Environment}

A lagoon is presenting a particular environment for navigation. Due to the conformation of the territory, inside a lagoon, there could be open areas characterised by shallow water without side limitations and areas where small channels are present [16]. In the first case, there is also the possibility to face wind-driven waves developing in shallow water. In the case of small channels, it is possible to observe the presence of currents induced by tidal changes or by the presence of river mouths [17]. All these aspects make the lagoon environment more difficult to model with respect to standard inland water cases (rivers, channels, or lakes), having more issues to tackle for a proper design of a vessel. In the North Adriatic area, lagoons are quite frequent and usually include also urban areas, as for example the famous Venice Lagoon. The Grado Lagoon (see Figure 1) is smaller compared to the one in Venice. However, it presents several urban areas and touristic points of interest. Moreover, the Grado Lagoon is also directly connected with small navigable rivers, combining the issues related to pure inland navigation with specific lagoon ones. Because of the small dimensions of the lagoon, the formation of waves can be considered negligible, registering extreme events that are not exceeding the 0.5 meters of wave height [18]. However, the aspects related to tide-induced and river-induced currents cannot be neglected. As mentioned, inside the Grado Lagoon, there are several touristic points of interest that can be connected with each other by means of a sustainable green passenger transport system that uses the lagoon waterways.

2.1. Main Routes. Previous studies identified more than one possible route inside the Grado Lagoon; between them, three are interesting for passenger transport (see Figure 2). The main hub for the transportation service is the village of Grado, and the routes connect the village with the touristic areas of Anfora di Porto Buso (Route 1) and Primero (Route 2) and the archaeological area of Aquileia (Route 3). In Table 1, the main characteristics of the routes are reported, highlighting the length, the mean water depth $h_{m}$, and the minimum water depth $h_{\min }$.

Each route presents some peculiarities due to the specific conformation of the lagoon across the selected tracks and of the infrastructures that can be located at the route endings. Route 1 is the longest one. It starts on the main large channel of the lagoon and develops through smaller channels characterised by shallow draught but without particularly heavy side limitations. Moreover, through this route, there is the possibility to install a shore electricity connection only in Grado. Therefore, this route is critical for the determination of the battery packs capacity. Route 2 is the shortest one and runs mainly across small narrow channels. Here, the confined water effects are more relevant and could present some problems related to the manoeuvring ability of the vessel rather than range. Route 3 is particular because to reach Aquileia, the final part is inside a narrow river. However, in this case, the main issues are related to the manoeuvrability of the vessel. The range issue is negligible, being possible to install a shore connection also in Aquileia. Based on these considerations, Route 1 has been identified as the most critical for the vessel operation in ZEM navigation. Therefore, Route 1 has been selected by operators for the first tests on the passenger craft prototype.

\section{Passenger Craft}

As a reference case for the study, an 11-meter inland-water vessel for the passenger transport inside the Grado Lagoon 


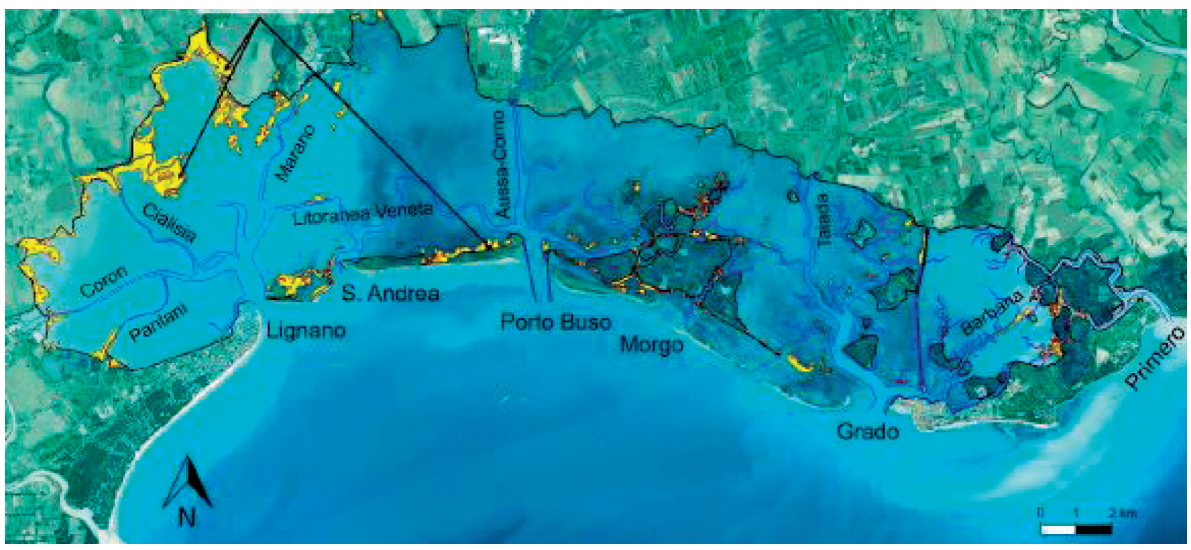

Figure 1: Overview of the Grado Lagoon.

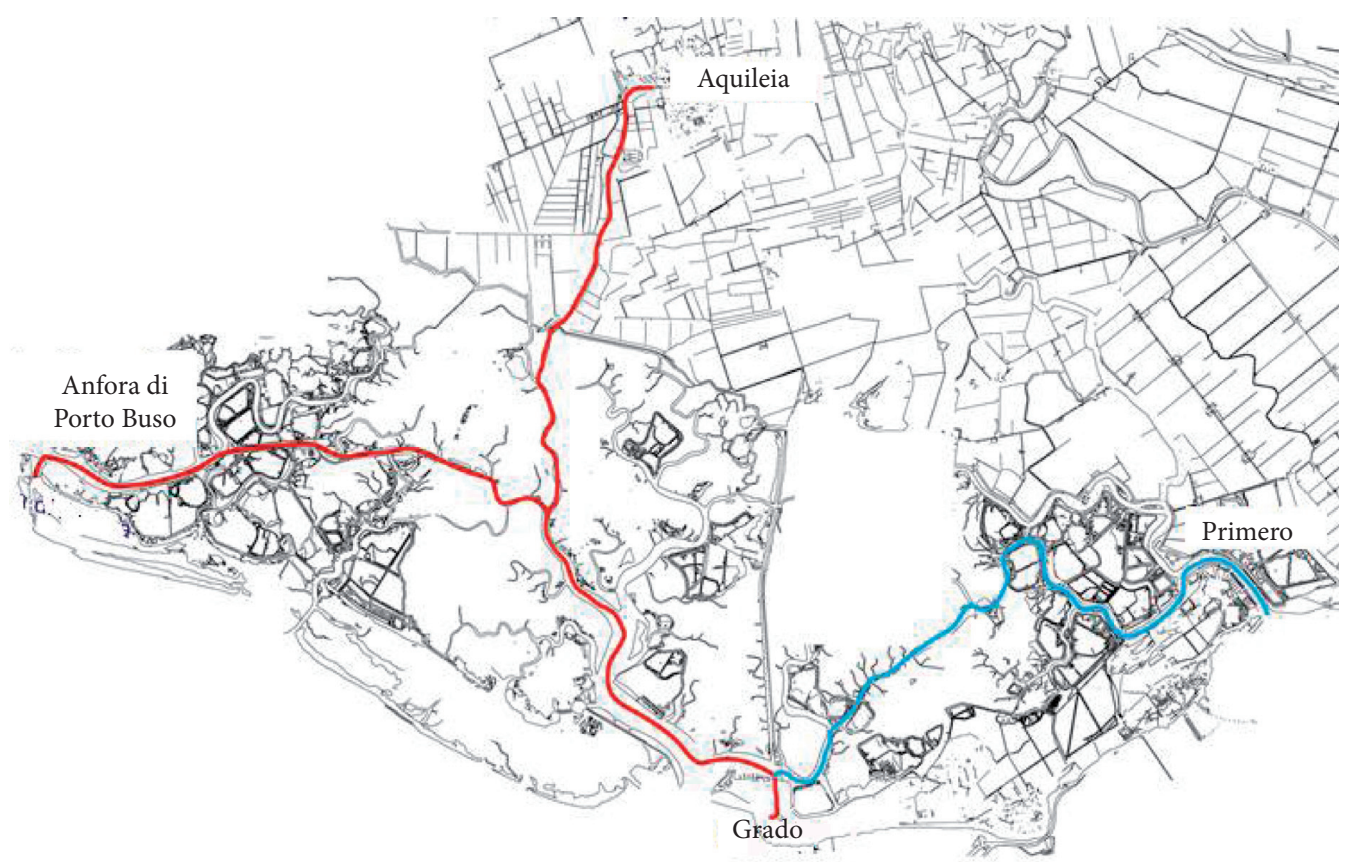

FIgURE 2: Routes of interest for passenger transportation in the Grado Lagoon.

TABLE 1: Main characteristics of the passenger transportation routes.

\begin{tabular}{lccccc}
\hline ID & Route & Length $(\mathrm{km})$ & $h_{\mathrm{m}}(\mathrm{m})$ & $h_{\min }(\mathrm{m})$ & \multicolumn{2}{c}{ Shore connection } \\
& & & 4.10 & 2.10 & Start \\
\hline Route 1 & Grado-Anfora di Porto Buso & 13.0 & 3.80 & 1.80 & Yes \\
Route 2 & Grado-Primero & 9.5 & 4.00 & 1.50 & Yes \\
Route 3 & Grado-Aquileia & 12.5 & No & Yes & Yes \\
\hline
\end{tabular}

has been considered (see Figure 3). The environment the unit has to face during his operational life leads to the necessity to have a shallow draught and, consequently, to not lose internal space, a flat bottom. However, the vessel was designed to sail also in unlimited waters, possibly reaching a top speed above 10 knots. These two issues refer to totally distinct hydrodynamic regimes that have different hull forms as an optimal solution. As a result, the final hull form is a compromise between the two duties the unit was supposed to perform. In Figure 4, the body plan allows seeing how the combination of the two operating profiles led to a hull form with a narrow waterline entrance angle to reduce wave-making resistance, combined with a small draught to avoid groundings in shallow water. Because of relatively high design speed, the aft-body presents a deeply immersed transom that is not ideal for sailing at low rates in shallow water. In the aft-body also a skeg is present, to grant course keeping stability to the vessel. Table 2 summarizes the main characteristics of the vessel and in Figure 5, an overview of the general arrangement is given. 


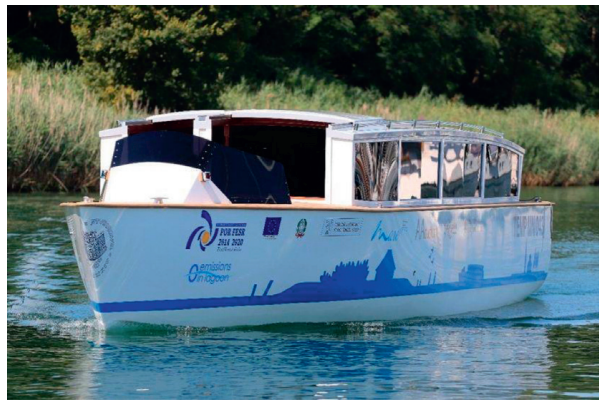

FIGURE 3: The prototype of the small passenger craft analysed in this study.
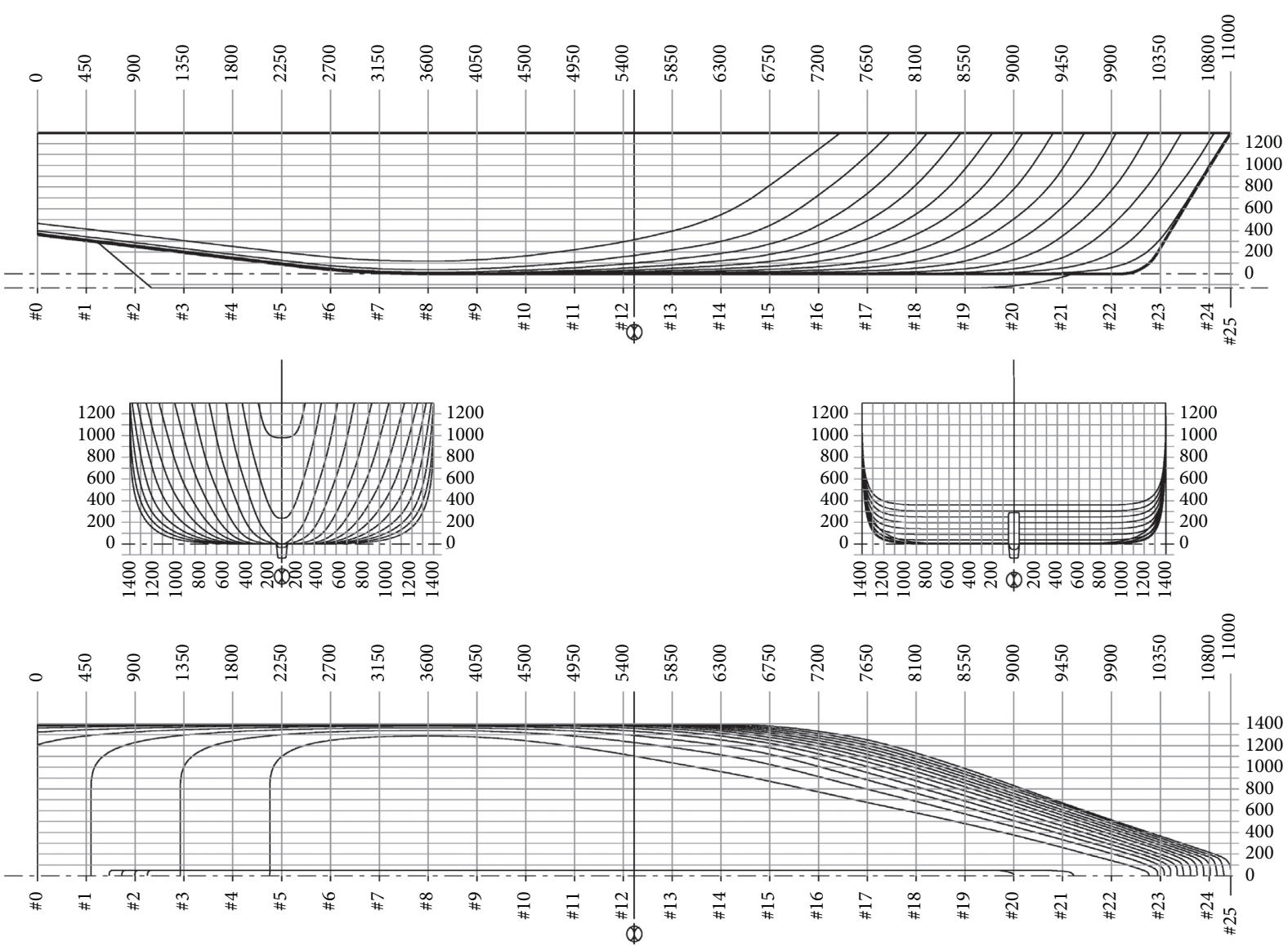

Figure 4: Body plan of the small passenger craft, showing the longitudinal buttocks (top), the transversal sections (middle), and the waterlines (bottom).

TABLE 2: Main characteristics of the passenger craft.

\begin{tabular}{lccc}
\hline Length overall & $L_{\mathrm{OA}}$ & 11.000 & $\mathrm{~m}$ \\
Length between perpendiculars & $L_{\mathrm{BP}}$ & 10.000 & $\mathrm{~m}$ \\
Length waterline & $L_{\mathrm{WL}}$ & 10.504 & $\mathrm{~m}$ \\
Breadth at design draught & $B$ & 2.769 & $\mathrm{~m}$ \\
Design draught & $T$ & 0.496 & $\mathrm{~m}$ \\
Displacement $\left(\rho=1.0 \mathrm{t} / \mathrm{m}^{3}\right)$ & $\Delta$ & 9.200 & $\mathrm{t}$ \\
\hline
\end{tabular}

3.1. Propulsion and Integrated Power System. The necessity to operate with a shallow draft did not allow to install a conventional propulsive system with shaft lines, propellers, and rudders. Instead of standard solution, a configuration with two electric steerable pods has been mounted onboard, having a fixed pitch three-bladed propeller with a diameter of 0.4 meters. The adoption of this kind of system implies to use a dedicated modelling for the propulsors, which is different from standard propeller case and is necessary to estimate with proper accuracy the propulsion power demand during transfer. The need to have a green profile for the vessel, suggested the adoption of a fully electric solution for the propulsion system. The Integrated Power System installed onboard satisfies the preliminary energy requirements, determined by a rough estimate of the loads due to 

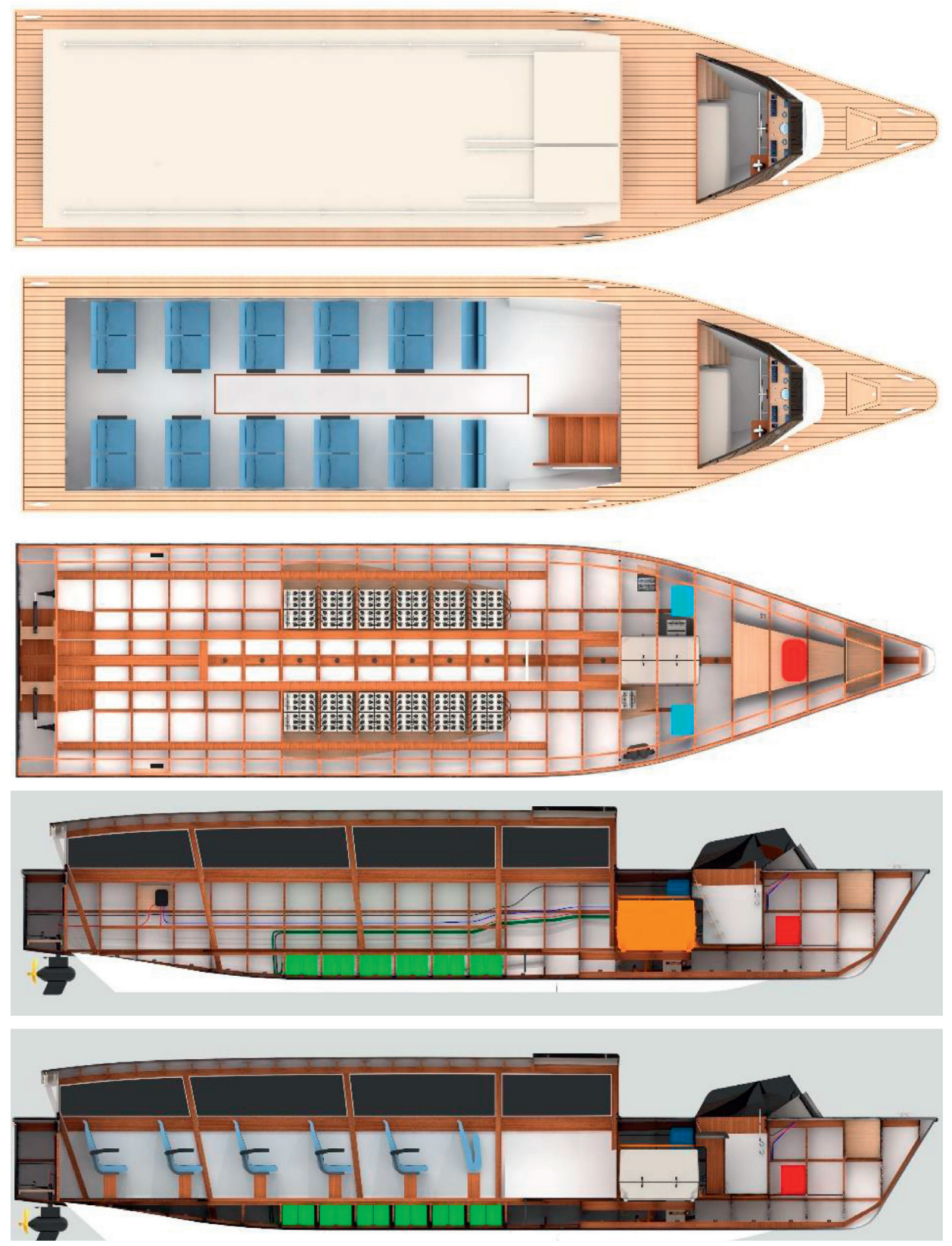

FIGURE 5: General arrangement plan and longitudinal sections.

the auxiliaries installed onboard. In such a case, the loads to add to propulsion are due to the manoeuvring system, the controls, and the battery chargers. Manoeuvring loads, estimated around $0.5 \mathrm{~kW}$, can be added to propulsive ones. Concerning the control ones, they are not relevant and refer to an independent low voltage $24 \mathrm{~V}$ circuit connected to a dedicated battery. For the first sizing, designers adopt a propulsive load of $1 \mathrm{~kW}$ at 3 knots and $7 \mathrm{~kW}$ at 6 knots, assuming deep-water conditions.

According to the above initial considerations, the IPS provided by an external supplier for the passenger craft results in a Low Voltage DC (LVDC) distribution system, selected for the fundamental easiness of the battery packs installation. A $48 \mathrm{~V}$ DC bus voltage connects the following subsystems: (i) Diesel generator with a power of $16 \mathrm{~kW}$

(ii) $\mathrm{AC} / \mathrm{DC}$ power converter to interface the Diesel generator with the LVDC bus

(iii) 2 battery packs providing $1124 \mathrm{Ah}$ and $53.95 \mathrm{kWh}$

(iv) 2 battery chargers to recharge batteries from both the onboard generator and the shore plug-in

(v) $2 \mathrm{DC} / \mathrm{AC}$ power converters to supply the electric propulsive motors of the steerable pods $(12 \mathrm{~kW}$ each)

(vi) $2 \mathrm{DC} / \mathrm{AC}$ power converters to supply electric power to the pods steering system

(vii) 2 contactors to configure the IPS 
An overview of the IPS is shown in Figures 6 and 7, highlighting that with the coordinated action of the two contactors, different operational profiles can be obtained:

(i) Battery charge at the shore

(ii) Propulsion with battery charge

(iii) ZEM propulsion

The design target for the propulsion system is the ZEM navigation. For this purpose, the designers dimensioned the battery package to ensure the ZEM navigation of the GradoPorto Buso track for four travels. As reference speed, the designers considered a constant mean value of 5 knots, also keeping a constant water depth of 2 meters. This leads to an estimation of the battery discharge of about $25 \%$ per each travel. This kind of assumption is simplistic since the vessel speed and the water depth change within the travel. For this purpose, to have a better evaluation of the power demand and, therefore, of the battery state of charge, it is necessary to build a more detailed simulation model of the passenger craft.

\section{Route Simulation Model}

As mentioned, the passenger craft has been designed and dimensioned according to general guidelines, and no specific simulation has been carried out during the concept design stage. In this section, the main details of the manoeuvring model for shallow water and the modelling of the propulsive drive will be described. An overview of the global simulation system is given in Figure 8, while the detail of the vessel simulation model is reported in Figure 9.

4.1. Manoeuvring Model. To capture and reproduce the behaviour of the vessel during the service along a specific route, it is necessary to simulate not only the standard fully ahead conditions (as performed in the early design phase of the vessel) but also all the intermediate states that arise during turning operations. For such a reason, at least the three degrees of freedom (3DOF) dynamics of the vessel on the horizontal water-plane should be described. Here, the following equations have been used to describe the vessel motions on the horizontal plane:

$$
\left\{\begin{array}{l}
\left(m+m_{u u}\right)=m r v+X \\
\left(m+m_{v v}\right) \dot{v}+m_{r v} \dot{r}=-m r u+Y, \\
m_{r v}+\left(I_{z}+m_{r r}\right) \dot{r}=N
\end{array}\right.
$$

where $m$ is the vessel mass, $I_{z}$ is the moment of inertia around $z$-axis, $u$ and $v$ are the velocity components in $x$ - and $y$-direction, $r$ is the velocity of rotation around $z$-axis, and $m_{i j}$ (with $i, j$ in $[u, v, r]$ ) are the added masses and added moments of inertia. In equation (1), the forces $X, Y$ and the moment $N$ are expressed with reference to the centre of gravity $G$ according to the reference system of Figure 10. In conventional manoeuvring models, the $X, Y$ forces and $N$ moment are divided into the specific contributions given by the hull, propeller, and rudder. Here, the vessel is not equipped with a conventional rudder plus propeller propulsion system but with a steerable pod. Therefore, the contributions of the propeller and of the submerged part of the pod can be considered as a single combined force, modifying the system in equation (1) as follows:

$$
\left\{\begin{array}{l}
\left(m+m_{u u}\right)=m r v+X_{\text {Hull }}+X_{\text {Pod }} \\
\left(m+m_{v v}\right) \dot{v}+m_{r v} \dot{r}=-m r u+Y_{\text {Hull }}+Y_{\text {Pod }}, \\
m_{r v}+\left(I_{z}+m_{r r}\right) \dot{r}=N_{\text {Hull }}+N_{\text {Pod }} .
\end{array}\right.
$$

The pod forces can be modelled starting from standard propeller curves and then corrected to simulate the presence of the pod housing with the same method that is used to model steerable thrusters in dynamic positioning applications [19]. The equations inside system (2) are integrated with a $4^{\text {th }}$ order Runge-Kutta method considering a fixed time step $\Delta t$ of 0.01 seconds, sufficient to capture the vessel dynamics adequately.

4.2. Hydrodynamic Forces. A detailed and accurate description of the hydrodynamic forces is essential to have a reliable simulation method for the passenger craft. In particular, once a manoeuvring simulator has to be developed, both the resistance in straight-ahead condition and the forces rising up during the manoeuvre have to be predicted. In this specific case, considering the working environment in a lagoon, the prediction of the hydrodynamic forces is complicated by the additional effect of shallow and restricted waters. The developed model can manage hydrodynamic forces evaluated in different ways, starting from empirical methods [20] up to the adoptions of forces derived from CFD calculations [21]. In any case, the hydrodynamic forces have to be inserted inside the system in equation (2) according to the following nondimensional formulations:

$$
\begin{aligned}
X_{\text {Hull }}^{\prime}= & X_{u}^{\prime} \dot{u}+X_{u}^{\prime}\left(u^{\prime}-u_{0}^{\prime}\right) \\
Y_{\text {Hull }}^{\prime}= & Y_{v}^{\prime} v^{\prime}+Y_{r}^{\prime} r^{\prime}+Y_{v \mid v}^{\prime} v^{\prime}\left|v^{\prime}\right|+Y_{v \mid r}^{\prime} v^{\prime}\left|r^{\prime}\right|+Y_{v \mid r}^{\prime} v^{\prime}\left|r^{\prime}\right| \\
& +Y_{r \mid r}^{\prime} r^{\prime}\left|r^{\prime}\right| \\
N_{\text {Hull }}^{\prime}= & N_{v}^{\prime} v^{\prime}+N_{r}^{\prime} r^{\prime}+N_{v|v|}^{\prime} v^{\prime}\left|v^{\prime}\right|+N_{v|r|}^{\prime} v^{\prime}\left|r^{\prime}\right|+N_{|v| r \mid}^{\prime}\left|v^{\prime}\right| r^{\prime} \\
& +N_{r|r|}^{\prime} r^{\prime}\left|r^{\prime}\right|
\end{aligned}
$$

where the $X_{i}^{\prime}, Y_{i}^{\prime}$, and $N_{i}^{\prime}$ are the nondimensional hydrodynamic derivatives that can be evaluated from empirical methods or derived from CFD calculations. The dimensional hull forces to be inserted into equation (2) are then obtained as follows:

$$
\begin{aligned}
& X_{\text {Hull }}=\frac{1}{2} \rho V^{2} L^{2} X_{\text {Hull }}^{\prime}, \\
& Y_{\text {Hull }}=\frac{1}{2} \rho V^{2} L^{2} Y_{\text {Hull }}^{\prime}, \\
& N_{\text {Hull }}=\frac{1}{2} \rho V^{2} L^{3} N_{\text {Hull }}^{\prime},
\end{aligned}
$$




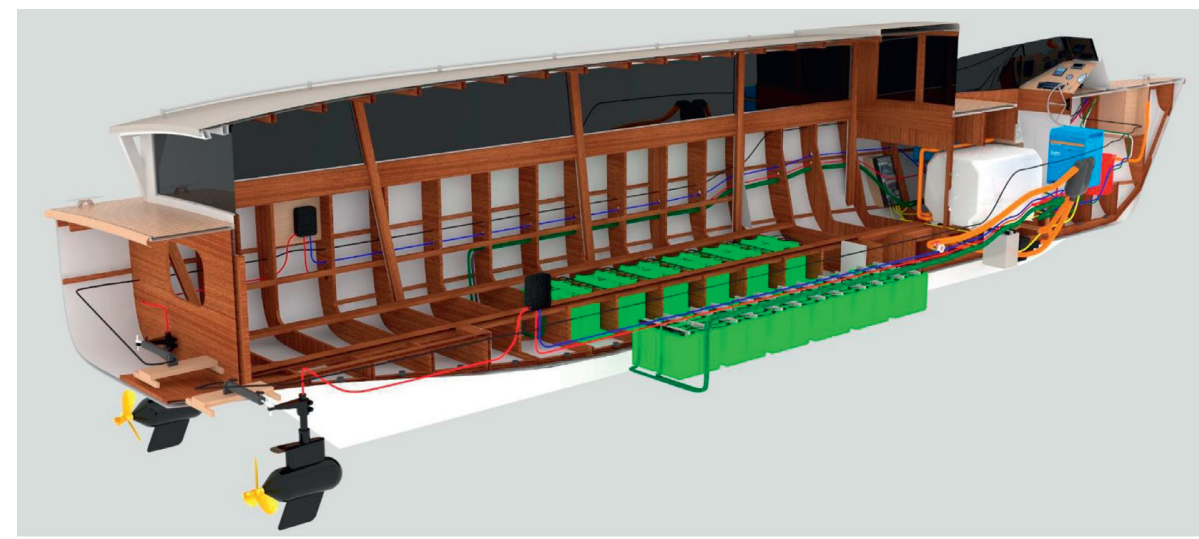

Figure 6: Rendering of the IPS system.

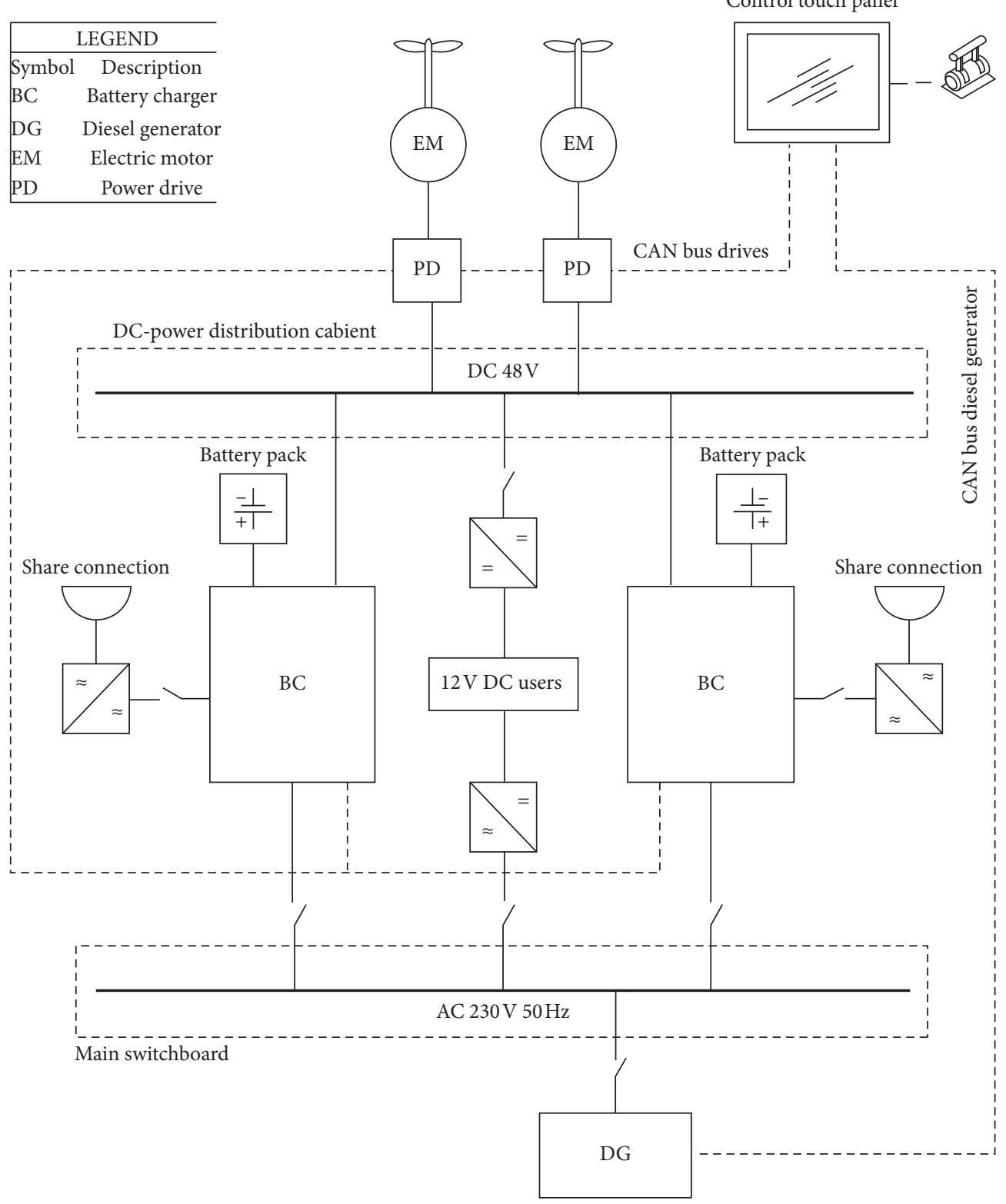

FIGURE 7: IPS system. 


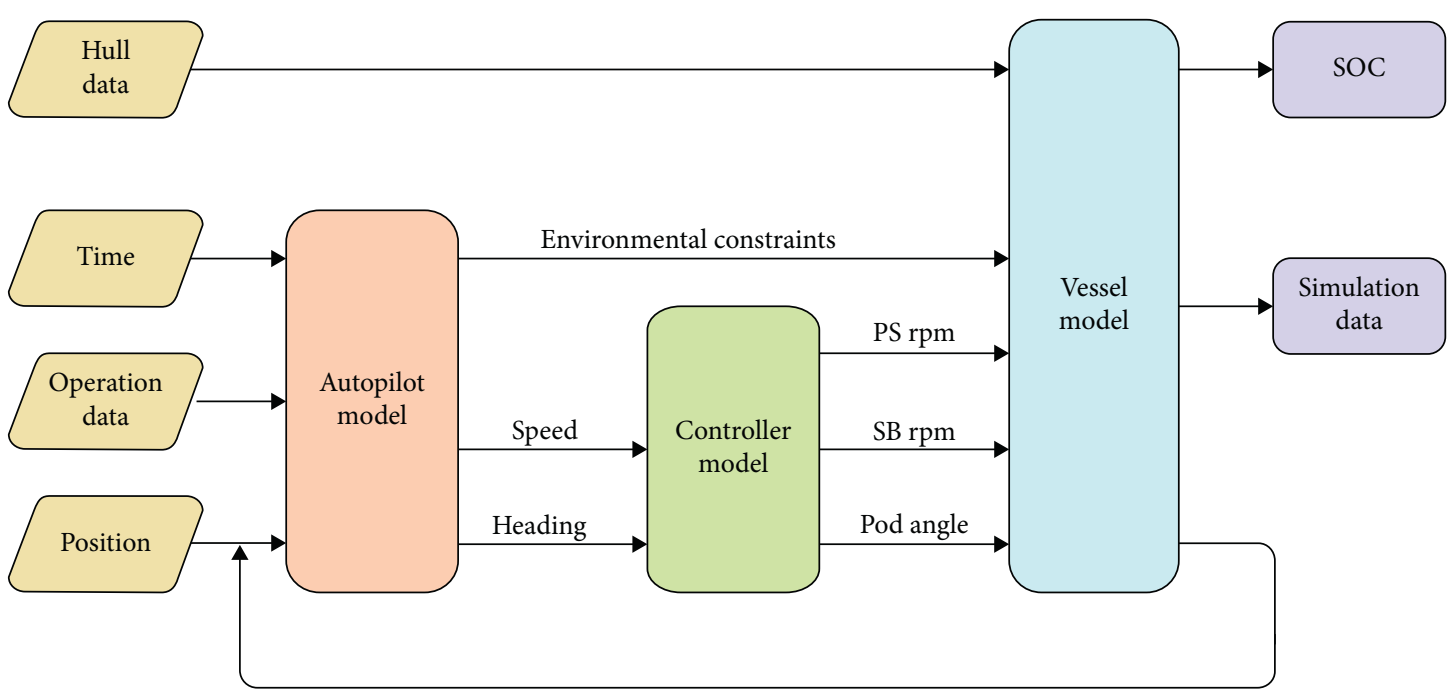

FIGURE 8: Global simulation model diagram.

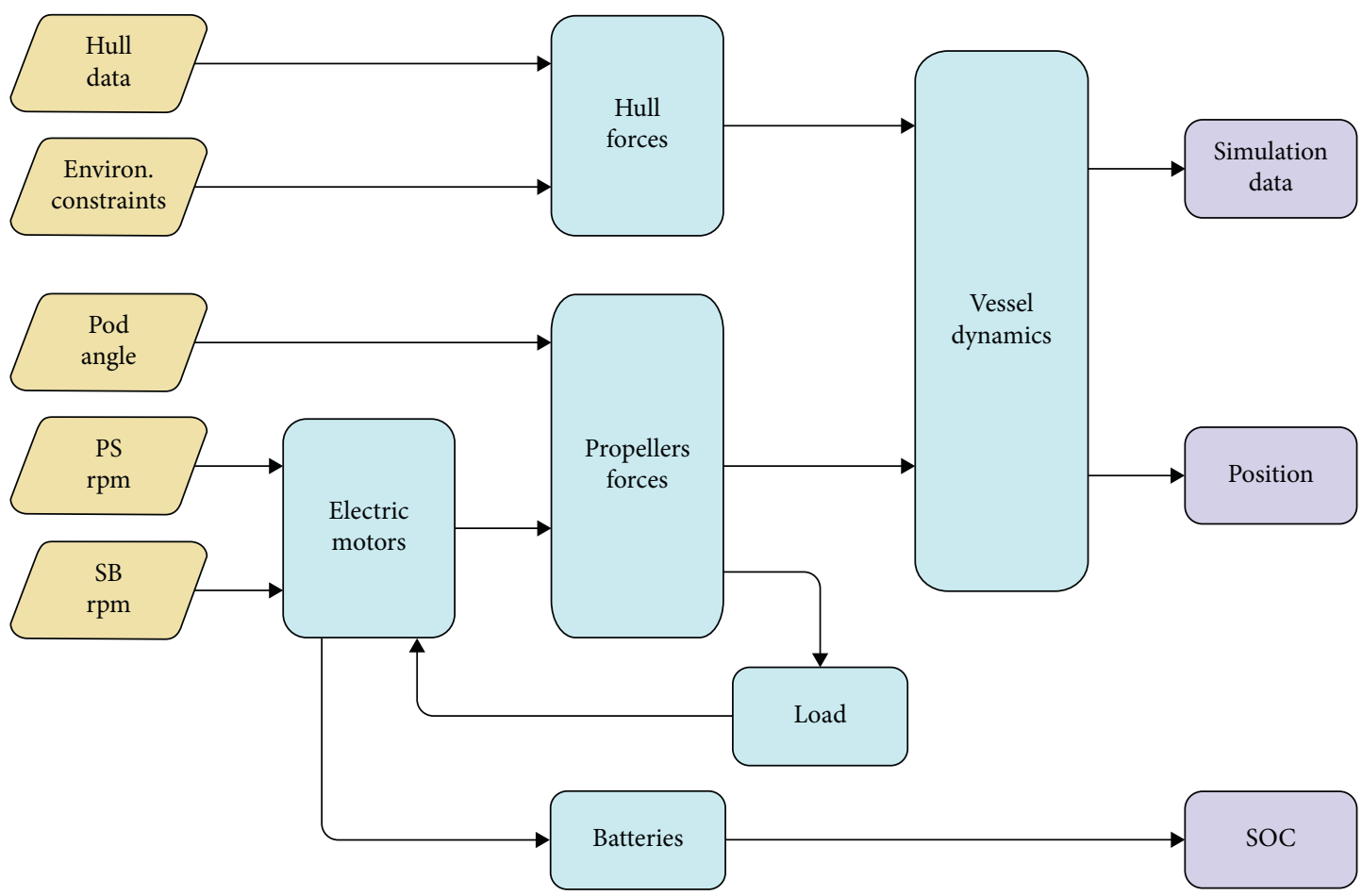

Figure 9: Vessel simulation model diagram.

where $V$ is the vessel speed, $\rho$ is the water density, and $L$ is the vessel length. If a shallow water case should be investigated, then the derivative of equations (3), (4), and (5) should be properly corrected [22]. CFD calculated derivatives do not need to be further correct since the calculations already include shallow-water modelling.

Equation (3) refers to manoeuvring forces only, which means the total resistance $R_{T}$ at the considered speed should also be added to the equation. Also, for the resistance, the statistic method can be used for a first estimation and corrected for shallow water effects. In the case of CFD derived curves, no correction is needed.
In the present study, use has been made of CFD computations for the determination of both shallow water manoeuvring forces and resistance.

In case of having an extra current present in the water, it has an effect only on the viscous part of the resistance of the ship, which means that a counteracting current has no effect on the wave-making resistance of the vessel. In such a case, $R_{T}$ is corrected considering also the restricted water effect according to the implemented methods $[23,24]$. The current is also influencing the manoeuvring forces, so the speed considered in equations (6), (7), and (8) is considering also the current effects. 


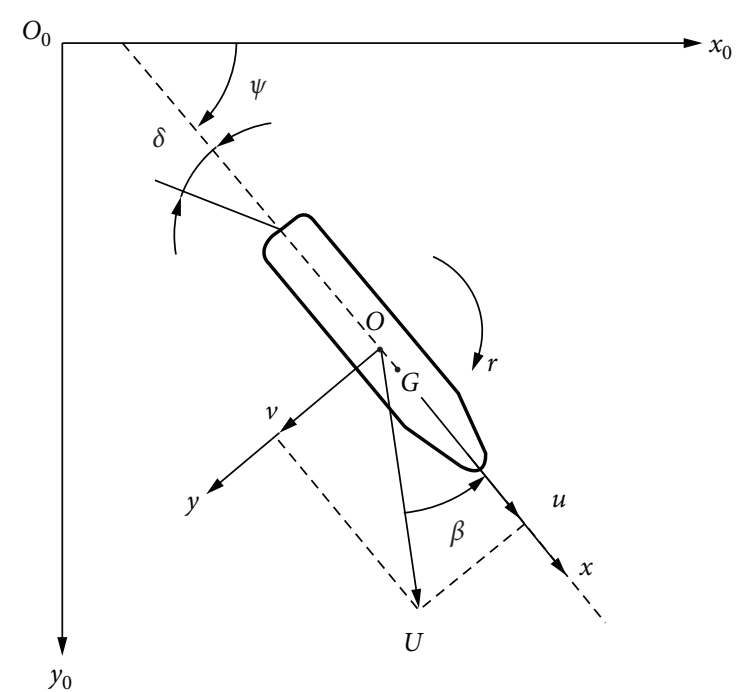

Figure 10: Reference system adopted for the simulations.

4.3. Autopilot, Steering, and Revolutions Control. To simulate the routes, a simple autopilot model has been implemented. The route is discretized with a number of waypoints the vessel has to follow. The waypoints are univocally identified with latitude and longitude values. The first waypoint is the starting position of the route, associated with the initial state of the vessel, which means the initial speed heading and the initial state of all the actuators and devices onboard. Besides the waypoints, it is necessary to provide the autopilot with a speed profile that has to be followed. Speed profile can be imposed with a time-dependent function or with a discrete array selecting the target speed between two consecutive waypoints. Through this study, the second option has been selected to perform the route simulations. The autopilot algorithm then evaluates the heading that is necessary to reach the next waypoint and the associated target speed. Once the vessel reaches a distance less than the vessel $L_{\mathrm{OA}}$ from the waypoint, the autopilot automatically selects the next waypoint as a target. The simulation stops when the last waypoint is reached.

As mentioned, the autopilot gives as output a target heading and a target speed. These two values are transmitted to the steering system and propulsive drive. Each system is composed of two controllers of PID type [25]. The control is based on the instantaneous error $e$, determined by the difference between the actual value and the required one at each simulation time step. Then the correction $\Delta x$ to the actual value is evaluated according to the following formulation:

$$
\Delta x=K_{p}(e)+K_{d}(\dot{e})+K_{i} \int_{0}^{T} e(t) \mathrm{d} t,
$$

where $K_{p}, K_{d}$, and $K_{i}$ are the control constants proportional to the error, to the derivative, or to the integral of the error $e$, respectively. For the passenger craft under analysis, several tests have been carried out to tune the parameters necessary to reproduce the steering device performances and the drive system.
4.4. IPS Model. To enhance the detailed hydrodynamic model developed for the passenger craft, simplified modelling of the IPS has been added to the simulation. The simplified model is oriented to evaluate the global power flow in the system, associating the state of charge of the battery packs to the effective power demand of the propulsors during ZEM navigation. For such a reason, only the components involved in the ZEM navigation profile have been considered: the motor drive and the battery packs. The developed model is based on the power balance principle on different elements, considering the efficiencies of each component according to data supplied by the manufacturers.

This kind of modelling has been selected mainly for two reasons. First, the adoption of more complex methods to simulate the electrical system requires the knowledge of more details on the components that are not available and specific competencies that are far from the scientific and technical background of the authors. Second, a more detailed model requires the adoption of a time step lower than what is necessary for the manoeuvring one, increasing a lot the total calculation time needed for a complete route simulation.

The two battery packs are composed of 12 lead-acid battery elements of $2 \mathrm{~V}$ and $600 \mathrm{Ah}$ each connected in series. The adopted modelling [26] is making reference to the battery discharge mode, expressing the nonlinear voltage of the batteries as follows:

$$
E_{\text {batt }}(t)=E_{0}-K \frac{Q}{Q-\int_{0}^{t} i d t} i^{*}-K \frac{Q}{Q-\int_{0}^{t} i \mathrm{~d} t} \int_{0}^{t} i \mathrm{~d} t,
$$

where $E_{0}$ is the constant voltage, $Q$ is the maximum battery capacity in Ah, $i$ is the battery current in $A, K$ is a polarization resistance in $\Omega$, and $i^{*}$ is a low pass filtered current. Then the state of charge (SOC) of the battery can be evaluated at each time step according to the following formulation:

$$
\text { SOC }=100\left(1-\frac{1}{Q} \int_{0}^{T} i \mathrm{~d} t\right)
$$

To tune the battery model, use has been made of the discharge diagrams of the batteries. In Figure 11, the nominal discharge characteristics of the batteries installed onboard are reported together with the simulated data with the above-mentioned model. The results show a good matching between the two curves.

With respect to the electric motor, use has been made of the efficiencies provided by the manufacturer as a function of load. In such a way, it was possible to convert the propeller absorbed power evaluated in the manoeuvring model in electric power for the electric model.

4.5. Model Validation. The developed route simulation model is complex and combines several aspects of the passenger craft, related to propulsion and electrical system. Moreover, due to the author's background as naval architects, the level of detail for the different issues of the simulation is different, giving more emphasis to the 


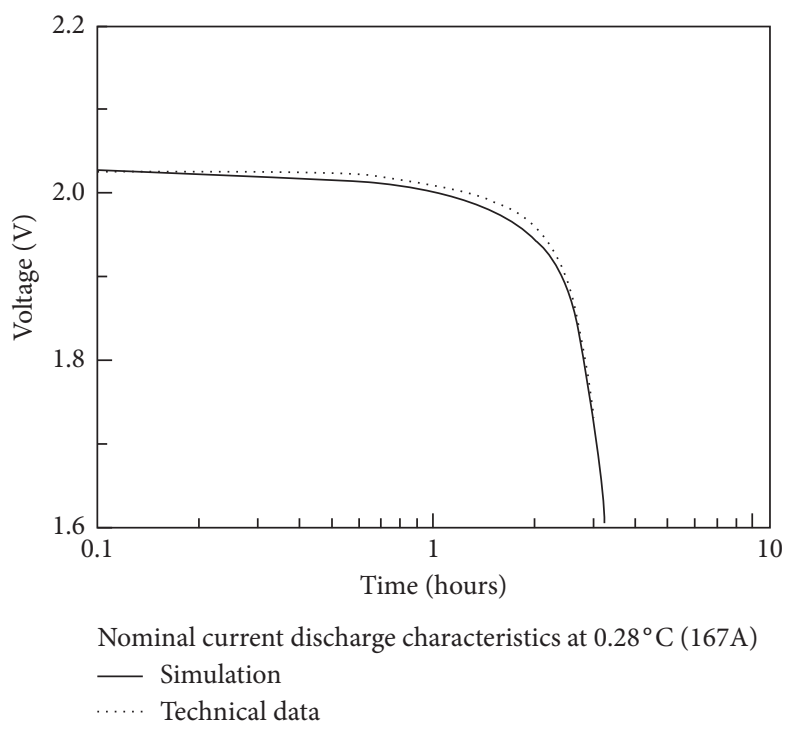

Figure 11: Comparison between nominal current discharge characteristics of the batteries installed onboard and the simulated data.

manoeuvring and hydrodynamic part with respect to electrical components. However, it is necessary to understand the reliability of the developed model. For this purpose, use has been made of data measured on a prototype of the small passenger craft, sailing on the route between Grado and Porto Buso. The trials have been executed at the design draught, corresponding to the main dimensions already reported in Table 2. During the trial, onboard data have been recorded with respect to position, speed, absorbed power, and state of charge of the batteries. The position is measured with the GPS, while the other data comes from lectures of the onboard instrumentation. The same route has been simulated with the developed models, setting as input parameters the tidal level measured that day and imposing the speed profile used during the test.

In Figure 12 a comparison is presented between the measured and the simulated data for the selected route. In the specific, the track, the speed, the absorbed power, and the battery SOC are reported. The speed profile of the passenger craft is well reproduced because the measured data were imposed as input for the simulation at the corresponding waypoints. What is important is that the simulation of the absorbed power, derived from the hydrodynamic model coupled with electric engine efficiency is almost in line with the measured data. Also, the SOC of the batteries is in good agreement with measured data, even though the proposed model for the electrical system is a simplified one. The obtained data are quite in agreement with the simulated one, giving enough confidence about the reliability of the proposed method.

4.6. Route Simulations Results. The comparison of the results between simulated data and trials highlighted that the simulation model is suitable to investigate more in detail the future service that the passenger craft will face. The trials were performed with a special agreement with the Coast
Guard, allowing the vessel to not respect the speed limits inside the lagoon. However, when the vessel performs the transportation service, it will be subjected to speed limitations of 6 knots in large channels and 3 knots in small ones. To investigate how the vessel will perform in the future operating profiles, the developed simulation tool can be used to evaluate the passenger craft performances. On this purpose, the limits due to the speed limitations have been imposed on all the three selected routes. In particular, for Route 1 the first part of the track can be performed with a maximum speed of 6 knots. Then, when the vessel is entering in the small channels the speed target is reduced at 3 knots. For Route 2, the first and the last segments of the track can be performed at 6 knots. The intermediate part has to respect the limit of 3 knots because of the speed limitations but also because of the narrow channels. For Route 3, the first segment is the same as per Route 1 on the main channel of the lagoon, considering a maximum speed of 6 knots. Then the route continues through the main channel at 6 knots while entering into the Natissa river. Here the target speed should be reduced to 3 knots. All the routes have been simulated considering the lowest tide level that is possible to face in the lagoon, considering a counteracting tidal current of 0.5 knots in such a way to simulate the worst possible case for the passenger transport service.

The simulations results are presented in Figures 13-15 for Route 1, Route 2 and Route 3, respectively. In the figures, the data corresponding to the absorbed power, the vessel speed, and the batteries SOC are shown. For Route 1, it is interesting to note how the speed profile imposed by the speed limitations in the lagoon influences the SOC of the batteries with respect to the tests performed on the same track. It can be noticed that the total travel time is increased from 1 hour and 22 minutes to 1 hour and 56 minutes, with a lower average speed. However, the batteries SOC is lower in the new simulation, with a final value of $83.63 \%$ compared to $87.93 \%$ of the trial simulation. This suggests that adopting a 

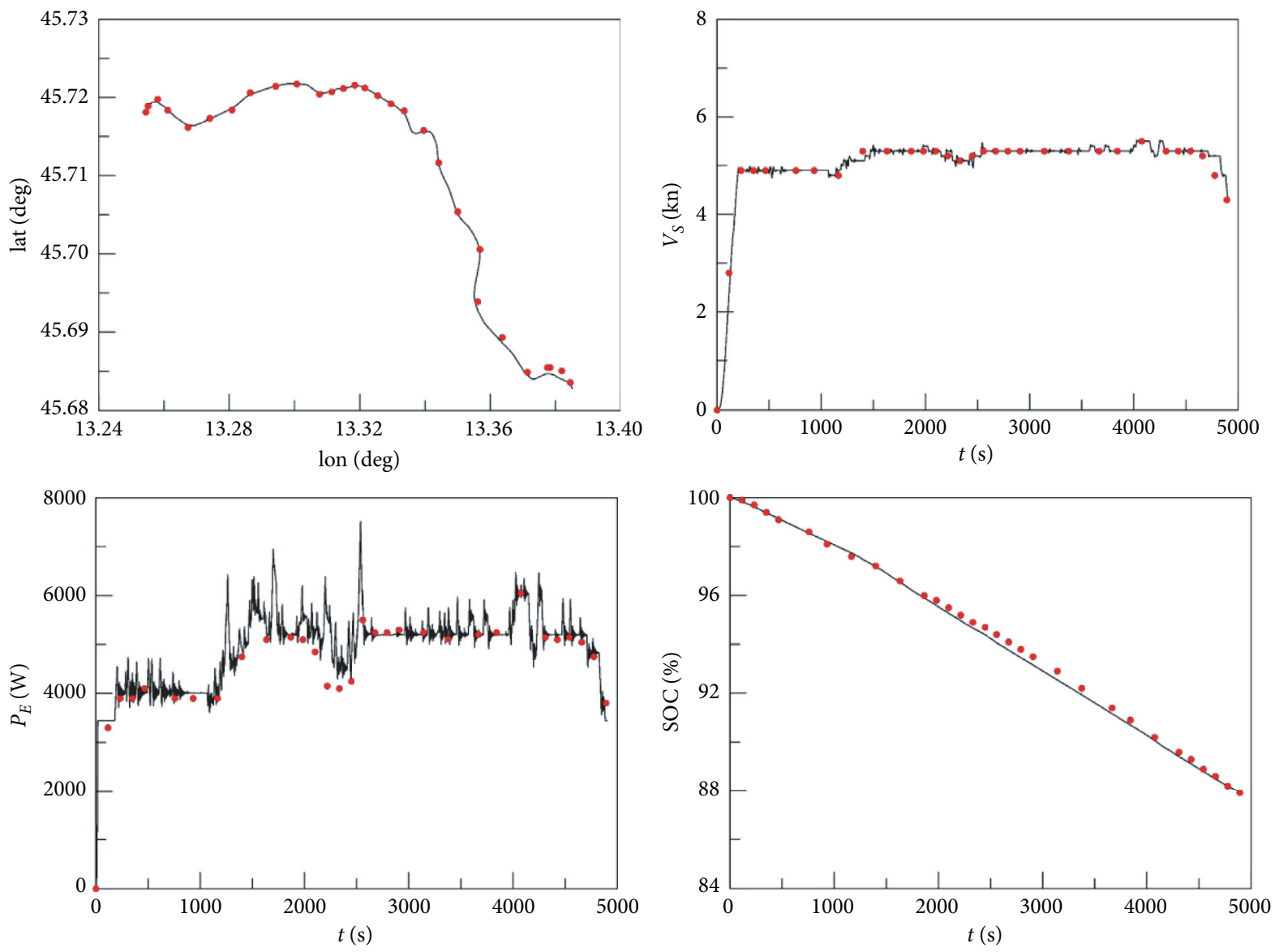

Figure 12: Comparison between measured and simulated data for the Grado-Porto Buso route.
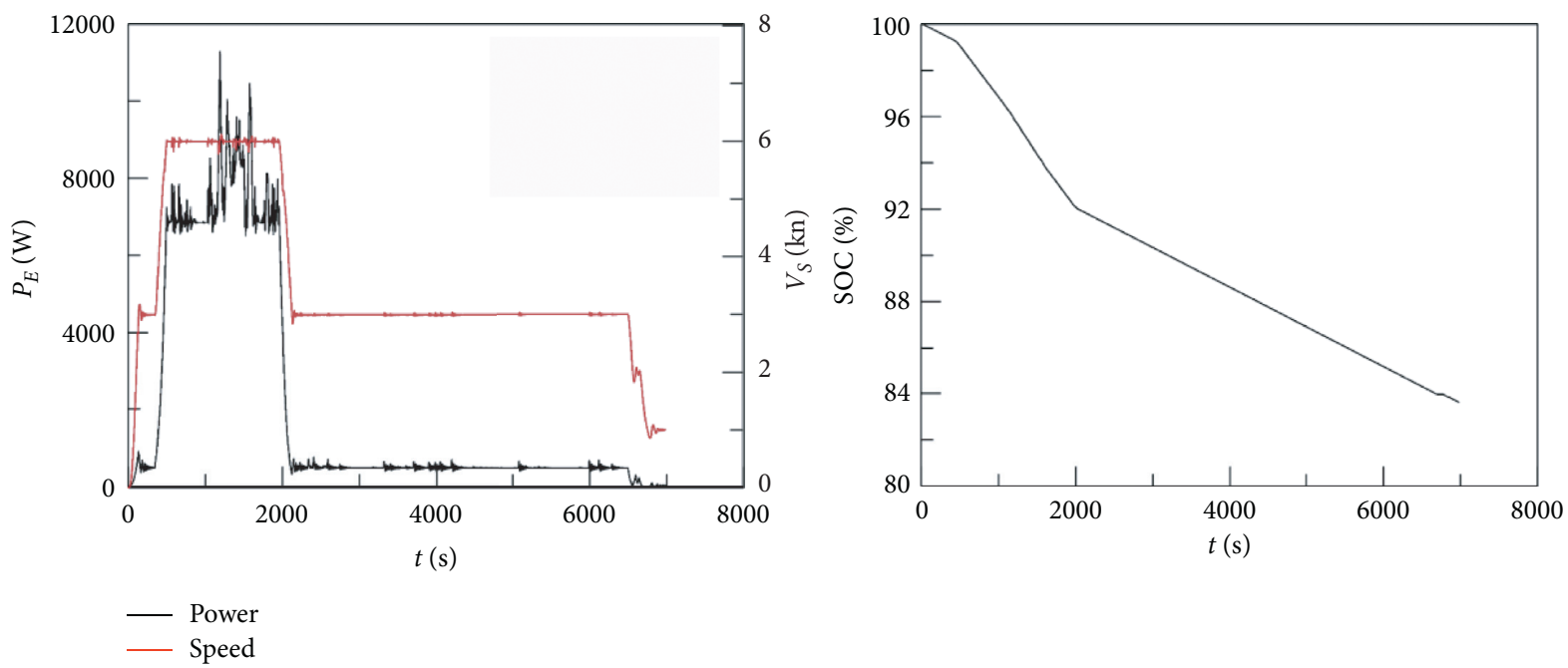

FIGURE 13: Results of the simulation on Route 1, highlighting speed, power, together with batteries SOC.

target speed profile as per the speed limitations inside the lagoon is not optimal for vessel range. This should be further investigated in future studies focused on it.

With respect to the other simulated routes, it can be stated that the final SOC is always higher than the case of
Route 1. Concerning the manoeuvring ability, the vessel was able to follow the established track without problems. According to the predicted SOC during the preliminary design of the vessel, the final SOC at the end of the considered routes was supposed to be $75 \%$, so probably the 

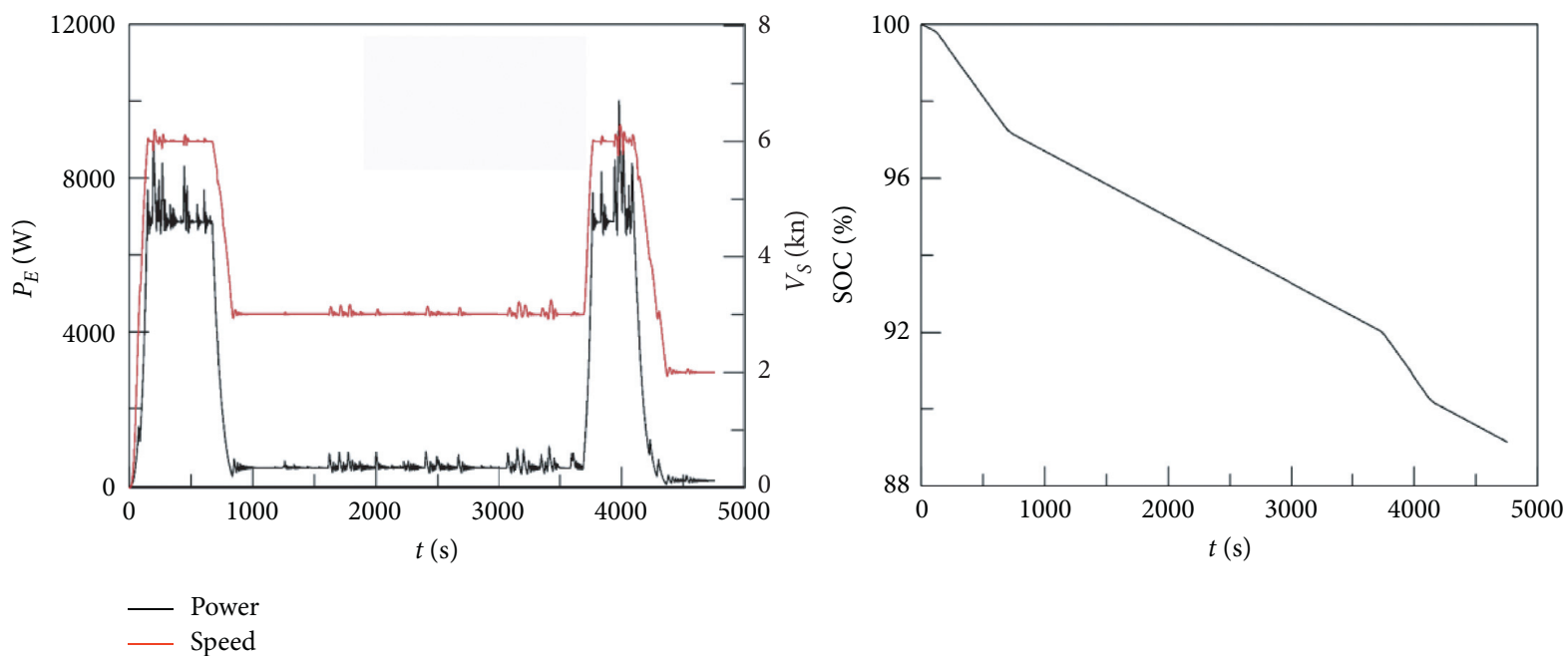

FIGURE 14: Results of the simulation on Route 2, highlighting speed, power, together with batteries SOC.
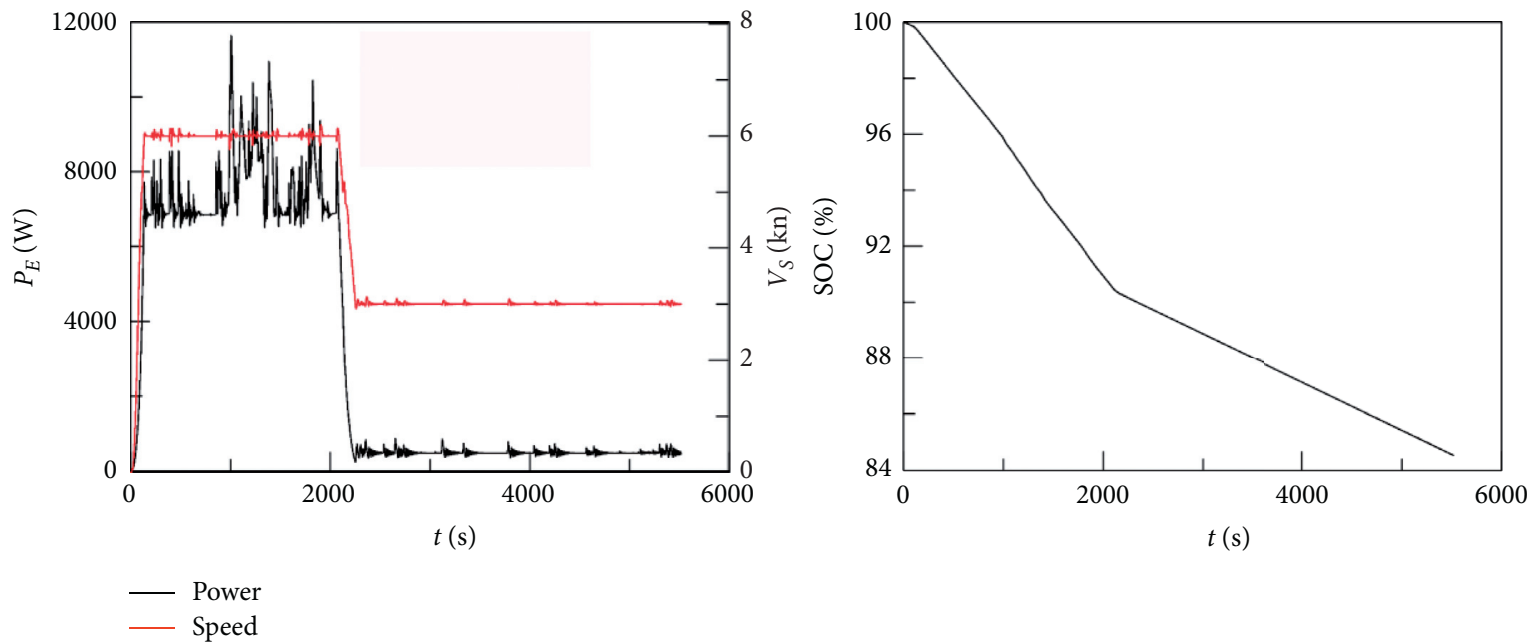

Figure 15: Results of the simulation on Route 3, highlighting speed, power, together with batteries SOC.

battery package installed onboard is somewhat oversized for the vessel duties in the specific environments. However, the determination of the effective SOC at the end of the route can give aid for the planning of the on-shore recharges.

\section{Conclusions}

The adoption of a fully electric solution is a good choice for enabling sustainable navigation in a protected environment and can be used for the transportation of passengers inside restricted water basins. The particular environment composed of shallow waters and narrow channels led to the need of proposing a sufficiently accurate simulation model to capture the hydrodynamic effects on the vessel manoeuvrability and to predict the absorbed power and battery pack state of charge.
In this paper, a model has been proposed for the simulation of both the cited issues and has been tested on a small passenger craft that operates in the Grado Lagoon. The model is in accordance with the measurements performed on the vessel prototype, both with respect to manoeuvring performances and energy demand.

Based on the validated model, all the routes of the vessel have been simulated, establishing the effective range of the passenger craft during the operational duties. The analysis of the obtained results for Route 1 highlights that the speed profile requested for operation gives less performance with respect to the speed profile adopted during the trials in the same conditions. This suggests that a further step can be done to find an optimal speed profile to optimize the range of the vessel on the selected routes.

The simplifications of the electrical system modelling are, for sure, a limitation to the accuracy of the electrical part 
of the model. Further study can be performed in this sense to improve even more the capability of the simulation tool developed for the passenger craft.

In conclusion, despite the assumptions considered in the electrical part of the simulation model, it can be stated that a new design tool has been set up in order to give a fast and reliable assessment of the ZEM performances of a vessel, since early design stages.

\section{Data Availability}

The data used to support the findings of this study are available from the corresponding author upon request.

\section{Conflicts of Interest}

The authors declare that there are no conflicts of interest regarding the publication of this paper.

\section{Acknowledgments}

This work was supported by ZELAG (Zero Emission Navigation LAguna di Grado) research program, funded by Regione Autonoma Friuli-Venezia-Giulia (Italy) with PORFESR (2014-2020, asse 1.3b).

\section{References}

[1] K. Folkert Boersma, G. C. M. Vinken, and J. Tournadre, "Ships going slow in reducing their $\mathrm{NO}_{\mathrm{x}}$ emissions: changes in 2005-2012 ship exhaust inferred from satellite measurements over Europe," Environmental Research Letters, vol. 10, no. 7, Article ID 074007, 2015.

[2] A. Petzold, J. Hasselbach, P. Lauer et al., "Experimental studies on particle emissions from cruising ship, their characteristic properties, transformation and atmospheric lifetime in the marine boundary layer," Atmospheric Chemistry and Physics, vol. 8, no. 9, pp. 2387-2403, 2008.

[3] IMO, Reduction of GHG Emissions from Ships: Third Imo GHG Study 2014, Final Report, MEPC 67/INF.3, International Maritime Organization, London, UK, 2014.

[4] J. M. Jacoby and J. Kann, "Global model simulations of the impact of ocean-going ships on aerosols, clouds, and the radiation budget," Atmospheric Chemistry and Physics Discussions, vol. 7, no. 4, pp. 5061-5079, 2007.

[5] Y. Cao, W. Zhang, X. Wang, L. Qian, and G. Qianb, "The relationship between atmospheric pollutant emissions and fuel qualities of inland vessels in Jiangsu Province, China," Journal of the Air \& Waste Management Association, vol. 69, no. 3, pp. 305-312, 2019.

[6] IMO, International Convention for the Prevention of Pollution from Ships, MARPOL 2017 Consolided edition, International Maritime Organization, London, UK, 2017.

[7] V. Bucci, A. Marinò, and A. Businaro, "The new hybrid small passenger craft for the Venice Lagoon," in Proceedings of the 18th International Conference On Ship And Shipping Research NAV 2015, Lecco, Italy, 2015.

[8] V. Bucci, A. Marinò, D. Bosich, and G. Sulligoi, "Inland waterway gas fuelled: an innovative proposal of a hybrid ship for the European network," in Proceedings of the IEEE ESARS 2015, IEEE, Aachen, Germany, March 2015.

[9] E. K. Dedes, D. A. Hudson, and S. R. Turnock, "Assessing the potential of hybrid energy technology to reduce exhaust emissions from global shipping," Energy Policy, vol. 40, pp. 204-218, 2012.

[10] V. Bucci, F. Mauro, A. Marinò et al., "An innovative hybridelectric small passenger craft for sustainable mobility in the Venice Lagoon," in Proceedings of the International Symposium on Power Electronics, Electrical Drives, Automation and Motion SPEEDAM, IEEE, Anacapri, Italy, June 2016.

[11] G. Hawksey, Hybrid Options, Electric Hybride Marine Technology International, Amsterdam, Netherlands, 2014.

[12] R. D. Geertsma, R. R. Negenborn, K. Visser, and J. J. Hopman, "Design and control of hybrid power and propulsion systems for smart ships: a review of developments," Applied Energy, vol. 194, pp. 30-54, 2017.

[13] A. Bernardini, C. Baroni, C. M. Legittimo et al., "An innovative concept for inland waterway vessels," Proceedings of the Technology and Science for the Ships of the Future, IOS Press, Amsterdam, Netherlands, pp. 35-42, June 2018.

[14] C. Nasso, U. la, S. Bertagna et al., "Integrated design of an ecofriendly wooden passenger craft for inland navigation," International Shipbuilding Progress, vol. 66, no. 1, pp. 35-55, 2019.

[15] F. Mauro, C. Nasso, U. la Monaca, and V. Bucci, "A simulation model for hybrid-electric inland waterway passenger vessels," Proceedings of the 19th International Conference on Ship and Maritime Research, NAV 2018, Trieste, Italy, June 2018.

[16] B. Kjerfve, Coastal lagoons, in Coastal Lagoon Processes, Vol. 60, Elsevier, Amsterdam, Netherlands, 1st edition, 1994.

[17] J. Peng and L. Ming, "Circulation dynamics and salt balance in a lagoonal estuary," Journal of Geophysical Research: Oceans, vol. 117, no. C1, pp. 1-16, 2012.

[18] M. Petti, S. Bosa, and S. Pascolo, "Lagoon sediment dynamics: a coupled model to study a medium-term silting of tidal channels," Water, vol. 10, no. 5, 569 pages, 2018.

[19] F. Mauro and E. Duranti, Effect of Propeller Modelling on Station-Keeping Thruster Allocation Strategy, Technology and Science for the Ships of the Future, IOS Press, Amsterdam, Netherlands, 2018.

[20] J. P. Hooft and U. Nienhuis, "The prediction of the ship's manoeuvrability in the design stage," in Proceedings of the SNAME Annual Meeting, New York, NY, USA, 1994.

[21] F. Stern, Z. Wang, J. Yang et al., "Recent progress in CFD for naval architecture and ocean engineering," Journal of $\mathrm{Hy}$ drodynamics, vol. 27, no. 1, pp. 1-23, 2015.

[22] K. Kijima, Y. Nakiri, Y. Tsutsui, and M. Matsunaga, "Prediction method of Ship maneuvrability in deep and shallow waters," in Proceedings of the MARSIM \& ICSM, p. 134, Tokyo, Japan, June 1990.

[23] A. B. Karpov, "Calculation of ship resistance in restricted waters," Trudy GII. T. IV, vol. 2, 1946 in Russian.

[24] L. S. Artjushkov, "Wall Effect Correction for Shallow Water Model Tests," North East Coast Institution of Engineers \& Shipbuilder, Transactions, vol. 85, no. 2, pp. 35-42, 1968.

[25] G. Lee, S. Surendran, and S.-H. Kim, "Algorithms to control the moving ship during harbour entry," Applied Mathematical Modelling, vol. 33, no. 5, pp. 2474-2490, 2009.

[26] O. Tremblay and L. A. Dessaint, "Experimental validation of a battery dynamic model for EV applications," World Electric Vehicle Journal, vol. 3, pp. 13-16, 2009. 